Revista Eletrônica de Ciência Política v. 9, n. 2 (2018), 102-121

DOI: $10.5380 /$ recp.v9i2.63768 https://revistas.ufpr.br/politica/

ISSN: 2236-451X

\title{
Company town e especulação imobiliária: um estudo de caso no município de Volta Redonda - RJ
}

\author{
Douglas Vinicius Franco \\ Mestrando, Universidade de São Paulo - USP
}

\begin{abstract}
O trabalho em tela mobilizou o arcabouço teórico e analítico fornecido pelas teorias sobre governança para explicar como ocorre o processo de especulação imobiliária no contexto de uma company town. Veremos por meio de um estudo de caso realizado no município de Volta Redonda que podemos explicar tal processo de valorização da terra por duas dimensões diferentes. A primeira considera a Companhia Siderúrgica Nacional como ator relevante por levar em conta suas posses, parte delas adquiridas por meio de seus recursos de poder quando ainda era uma indústria estatal. Já a segunda dimensão considera os aspectos que se relacionam com o tipo de regulação do território gestado no modelo de uma "cidade empresa" e a mobilização de atores privados em conexão com a recém criada prefeitura. Veremos ao final, que mesmo levando em conta essas duas dimensões que lançam luz à diferentes atores e instituições, ainda assim, é possível verificar mecanismos para a especulação imobiliária em ambas. Esses diferentes olhares nos darão as primeiras pistas para investigar como ocorrem os processos mais atuais de valorização da terra em um município dotado de tantas particularidades.
\end{abstract}

Palavras-chave: company town; especulação imobiliáriA; Volta Redonda; CSN.

\section{INTRODUÇÃO}

O presente artigo visa mobilizar o arcabouço teórico e analítico fornecido por autores que discorrem sobre processos de governança e em especial sobre governança urbana, para pensar de modo mais amplo como ocorreu - e ainda ocorre - o processo de valorização da terra no município de Volta Redonda, localizado na região sul do estado do Rio de Janeiro. Este município foi marcado por uma trajetória histórica bastante peculiar que será brevemente relatada com intento de clarificar o tipo de formação e gestão do espaço urbano que esteve presente nesta localidade. Trata-se de um município gestado a partir de uma lógica de company town, fenômeno pouco tratado pela literatura da Ciência Política brasileira e cujo termo por vezes é traduzido como "cidade empresa" ou "cidade operária". Dentro dos aspectos singulares da formação do município em questão, salientamos que este foi 
sede da Companhia Siderúrgica Nacional (CSN) e isso trouxe substantivos impactos para a cidade e seus habitantes. Por se tratar de uma cidade concebida após a instalação da usina siderúrgica, boa parte das expectativas do poder público municipal, dos trabalhadores e de parcela dos cidadãos passaram a gravitar em torno das ações e decisões da CSN, transformando essa empresa em um ator central e com demasiados recursos de poder.

O pano de fundo que guia a análise começa a ser considerado a partir de 1941, quando assuntos relativos à produção de aço estavam na ordem do dia para o governo federal. Período este que ficou conhecido como o Estado Novo, foi caracterizado pelas intensas mudanças nas instituições da administração pública brasileira e no modelo econômico adotado antes da Revolução de 30. Essas transformações estavam, em parte, alicerçadas no processo de profissionalização da burocracia e no investimento em indústrias estatais de base como ferramentas para o desenvolvimento da nação. Nesse contexto iniciou-se o processo de planejamento da grande indústria siderúrgica que posteriormente seria abrigada no distrito de Volta Redonda. Em 9 de abril de 1941 é aprovado o primeiro Estatuto da CSN e é considerada a data oficial de fundação da empresa (MOREL, 1989).

Nosso intuito não é a pura reconstrução histórica de parte da formação do município, que oportunamente delimitamos entre os anos de 1941 até 1954 por abarcar especificamente o momento em que a cidade era gerida pela indústria siderúrgica estatal. $\mathrm{O}$ argumento é que, se quisermos pensar de modo mais amplo como ocorre o processo de especulação imobiliária em uma company town, utilizando o caso de Volta Redonda, precisamos verificar determinados processos-chave que orientaram (I) a organização territorial do município a partir da lógica de uma cidade-empresa - considerando principalmente a acumulação de ativos imóveis por parte da antiga estatal; e (II) a atuação de atores centrais que se interessaram pelo espaço urbano nesse período específico. Grupo de atores esses, como veremos, também adquiriram vantagens oriundas da exploração da terra.

A justificativa para a pesquisa é sustentada pela singularidade do caso, que serve de contribuição para pensar a especulação no contexto de uma company town. A principal hipótese reside no fato de que o modelo de cidade operária gestado no antigo distrito de Volta Redonda no período de 1941 até 1954, conferiu, de modo mais drástico, benefícios à CSN. Adotamos como exemplo para ilustrar tal fato um vasto conjunto de glebas ociosas denominadas de Aero Clube, localizadas nas dependências do município e assenhoradas pela empresa até os dias atuais, mesmo após sua privatização em 1993.

Embora tais benefícios não sejam uma novidade, se considerarmos os recursos de poder conquistados pela Companhia, amplamente evidenciado na literatura (MOREL, 1989; PALMEIRA, 2012; LIMA, 2013) traremos nesse artigo um fato inusitado e parcialmente esquecido: esse modelo também beneficiou outros atores privados, que consolidaram uma forte rede de governança em torno do espaço urbano para além da própria empresa, rede essa sustentada por meio de práticas irregulares como a produção e aprovação de loteamentos clandestinos e outras irregularidades que certamente contribuem para pensar a especulação no município.

Considerando essa breve exposição, colocamos a seguinte questão para o leitor: de que maneira o modelo de gestão de uma company town contribui para pensar processos 
mais amplos de especulação do valor da terra no município de Volta Redonda?

Gostaríamos de salientar que esse artigo tratará de uma conjuntura crítica (COLLIER, 2004) bastante específica. Portanto, nosso grau de generalização para explicar a valorização da terra nos dias atuais ainda é limitada, uma vez que o processo de mapeamento dos principais atores envolvidos com esse processo ainda é heterogêneo e de caráter exploratório. Todavia, evidenciamos em uma relação de path dependence (NORTH, 1990) para explicar a valorização nesse contexto específico. Isso quer dizer que para além de afirmar que "as instituições importam", nesse estudo, "a história importa" (HOCHMAN, 2013) e, portanto, torna-se um sinônimo e uma ferramenta analítica da primeira afirmação.

Nesse momento, conseguimos cobrir os principais atores envolvidos com a especulação no horizonte temporal que definimos, a saber, de 1941 até 1954. Desta conjuntura em diante, mapeamos as ações e decisões diretamente ligadas à CSN, por ser, de fato, o ator que claramente dispõe de maiores recursos de poder perante o território de Volta Redonda. A ideia é que novos trabalhos sucessores a esse em tela tragam com mais clareza a posição dos outros atores, menos importantes, mas que também explicam a especulação imobiliária no contexto de uma cidade empresa, por meio de novos processos que se transformaram no curso da história após 1954, como a emancipação do município e o aparente fim do modelo de company town.

Além desta breve introdução, o presente artigo conta com outras quatro seções. A primeira visa clarificar a relação estabelecida entre o modelo de company town e o espaço urbano. Na segunda seção, apresentaremos as estratégias metodológicas, as lentes de análise e a revisão teórica pertinentes ao estudo. A terceira seção apresenta as duas diferentes dimensões do estudo de caso que nos auxiliam no entendimento dos processos relacionados à especulação imobiliária em Volta Redonda. Por fim, uma breve conclusão sobre a pesquisa realizada.

\section{MODELO COMPANY TOWN E SUA RELAÇÃO COM O ESPAÇO URBANO}

A presente seção destina-se a elaboração de um breve inventário sobre algumas características do modelo de company town gestado em Volta Redonda à luz de sua relação com o espaço urbano.

Em pouco mais de uma década, o distrito de Volta Redonda se estabeleceu como a localidade mais expressiva em termos de adensamento populacional na Mesorregião Sul Fluminense ${ }^{1}$, muito em virtude das atividades de uma única indústria. Segundo Regina Morel "em 1942, a CSN já empregava 6.164 trabalhadores, portanto mais que o dobro de habitantes do distrito, ocupados na construção da usina e da cidade" (MOREL, 1989, p. 51). Em 1950 o município possuía uma população de 39.964 habitantes, rendendo-lhe o apelido de "Cidade do Aço" por depender exclusivamente da CSN (idem, 1989).

Essa característica de cidade monoindustrial conferiu ao município a qualidade de

\footnotetext{
${ }^{1}$ É importante destacar que a Mesorregião Sul Fluminense é, depois da Mesorregião Metropolitana, a mais industrializada do estado do Rio de Janeiro.
} 
uma cidade operária, sendo esse fenômeno discutido pelo sociólogo Raphael Lima (2013) em seus estudos sobre o sistema de relações entre a CSN e o município de Volta Redonda. Trata-se de um ambiente com uma formação sociopolítica muito específica e por esse motivo Volta Redonda se tornou inclusive área de segurança nacional (MOREL, 1989; PALMEIRA, 2012; LIMA, 2013).

É interessante notar também que o modelo de cidade operária guarda relações muito profundas com a produção do espaço urbano. Segundo Soeli Lima (2008) a primeira associação que se faz a esse modelo é a de uma pequena cidade na qual um conjunto de equipamentos comunitários, incluindo habitações, edifícios, escolas, hospitais e áreas de lazer pertencem a uma companhia e onde é exercido controle sobre entradas e saídas de pessoas, de tal forma que se configure um núcleo urbano fechado. Quanto à relação da formação de uma cidade operária com os processos gerais de urbanização, consideramos o que diz Garcês (2003) em seu estudo de caso sobre a mineração, realizado no Chile:

Las company towns se instalan em la historia del urbanismo como uma manufactura urbana organizada por un proyecto de ingeniería y arquitectura que formaliza y distribuye las edificaciones del área industrial, los equipamientos y la residencia, en un conjunto que alcanza uma organizacion física, productiva y social. El modelo es adecuado a uma función productiva principal como es la explotación de materias primas y la manufactura industrial, al mismo tiempo que funciona a la modelacion de un grupo social excluido de otras actividades y manifestaciones urbanas que aquellas que le entrega la companhia (apud LIMA, 2008, p. 2).

Para potencializar nosso argumento e responder à questão que guia este estudo, podemos afirmar que mesmo após a emancipação de Volta Redonda em 17 de julho 1954 (MOREL, 1989), as diretrizes de desenvolvimento urbano estiveram intrinsicamente ligadas ao desenvolvimento da própria usina siderúrgica e isso é evidenciado em um primeiro plano diretor conhecido como Plano Estratégico de Desenvolvimento Integrado (PEDI) aprovado em 1977. Esse normativo funcionou como uma espécie de instrumentalização legal de organização do espaço físico do município (LIMA, 2013). Com esse plano diretor a CSN impôs também um conjunto de limitações estruturais capazes de interferir na configuração política, econômica e cultural do território de Volta Redonda (idem, 2013).

O autor Lima (2013), na verdade, está se referindo ao modo como a cidade foi produzida: a CSN administrou uma fração do território do município de modo mais drástico por aproximadamente quinze anos, que foi justamente a lacuna temporal entre a chegada da estatal, que gerou o modelo company town, até o efetivo desenvolvimento do poder público municipal. Ainda que emancipado, as diretrizes de desenvolvimento da CSN e do município ocorriam de forma coordenada pelos normativos prescritos no PEDI. Com isso, queremos defender que mesmo após o aparente fim do modelo de gestão de company town, a cidade ainda continuava condicionada a esse modelo de gestão do espaço urbano.

Durante o formato de cidade operária, as incumbências relacionadas ao provimento de serviços urbanos e de utilidade pública estiveram a cargo da CSN controlada pelo governo federal, conforme relaciona o Boletim de Serviço $n^{\circ} 2$, de 7 de janeiro de 1948 (MOREL, 1989, p. 128): 
a) conservação das estradas e ruas;

b) manutenção e conservação de parques e jardins;

c) horto florestal e reflorestamentos;

d) serviço de limpeza urbana;

e) manutenção das redes de água e esgoto da cidade;

f) manutenção das redes de distribuição de energia elétrica;

g) transportes coletivos; e

h) serviço de polícia e bombeiros da cidade.

O período que propomos analisar (1941-1954) caracteriza uma lacuna, um dado momento em que a estatal fica encarregada de organizar o território em diversos sentidos: construindo casas para os operários, clubes de lazer, escola técnica, além de realizar urbanização de áreas e oferecer transporte público. Morel (1989) detalha que isso tudo faz parte de um projeto maior, que é a construção da "família siderúrgica". Como é de se esperar, o acesso à moradia e outros serviços públicos somente era concedido aos funcionários da CSN, em um tipo de modelo que aparentava possuir traços da "cidadania regulada" ${ }^{2}$ (SANTOS, 1979). Isso gerou alguns efeitos de exclusão para outros habitantes (outsiders da regulação da empresa), em um padrão bastante peculiar de segregação urbana e desigualdade de acesso aos serviços. Em 1953 a CSN passou a se preocupar com os gastos urbanos da parte que ela administrava e "percebeu que poderia ter na Prefeitura um ótimo sócio para dividir os encargos urbanos" (MOREL, 1989, p. 262).

A aparente superação do modelo de company town começou a dar sinais quando o município se emancipou em 1954 e o poder público municipal passou a assumir gradualmente as responsabilidades pelas áreas não geridas pela CSN. Não foi um processo automático, mas algo que aconteceu lentamente e com alguma ambivalência entre as administrações. Por algum tempo havia a Prefeitura municipal e a "prefeiturinha" da CSN (MOREL, 1989). Essa transição é muito interessante, pois nos permite verificar ações que ocorreram fora da fração do território gerido pela CSN. Embora o período que sucede a emancipação não esteja amplamente contemplado nesta análise, adiantamos que a maneira como a CSN administrava o território permitiu, dentre outras coisas, uma expansão desordenada de alguns bairros cuja regulação não era exercida pela estatal. Isso favoreceu a ação de loteadores clandestinos nessas áreas, que vislumbraram a oportunidade de realizar bons negócios (idem, 1989).

Esses fatos geraram um elemento importante que deve ser observado neste estudo. Trata-se da cristalização de dois modelos de cidade: a "Cidade Nova" gerida e regulada pela CSN e a "Cidade Velha" que aparentava não possuir qualquer tipo de regulação até a emancipação do município, sendo o segundo modelo o principal alvo dos loteamentos clandestinos (MOREL, 1989). Essa dicotomia nos ajuda a explicar como diferentes atores agiram no sentido de explorar o espaço urbano sem a regulação fornecida pelo modelo de

\footnotetext{
${ }^{2}$ Expressão de como os direitos de cidadania social se constituíram no país; não representando um código de valores políticos (pertencimento à comunidade política nacional), mas um sistema de estratificação ocupacional definido por norma legal (ocupações definidas por lei), via regulamentação de novas ocupações e dos direitos associados a elas.
} 
cidade empresa.

O intuito de trazer para o debate algumas das características do modelo de company town e sua relação com o espaço urbano é explicar como alguns atores privados, mas principalmente, como a CSN foi capaz de acumular terras no município em questão, transformando esses ativos em um enorme potencial para especulação. O mapa abaixo é representativo da quantidade de posses acumuladas pela Companhia no espaço urbano do município:

Figura 1 - Mapa de Volta Redonda (2002) - área urbana em azul e as terras de propriedade da CSN estão em cor-de-rosa

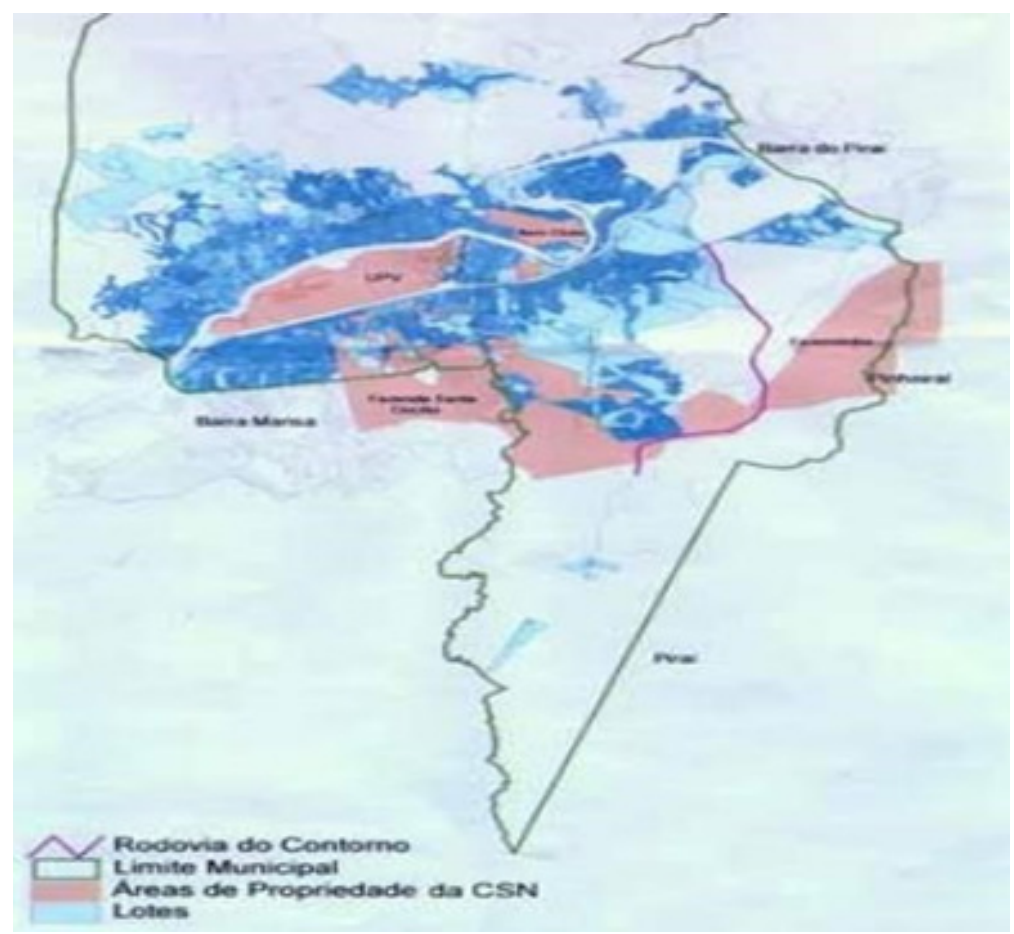

Fonte: Sindicato dos Engenheiros de Volta Redonda SENGE/VR In: Palmeira 2012, p. 199.

Responder questões associadas às suas posses é um caminho para pensar em processos mais amplos que se relacionam com a especulação do valor da terra, além do próprio planejamento urbano - no sentido de pensar os conflitos em torno da utilização do espaço urbano. A próxima seção destina-se a apresentação da metodologia e do arcabouço teórico e analítico mobilizado nesta análise.

\section{METODOLOGIA, REVISÃO DE LITERATURA E LENTES DE ANÁLISE}

Realizar uma análise qualitativa em torno do processo de organização de uma cidade empresa é viável não para criar generalizações, mas para garantir profundidade no conhecimento apreendido, de modo a contribuir para o debate sobre o modelo de company 
town em uma cidade brasileira. A análise proposta nos permitirá identificar e interpretar o modo como atores públicos e privados, se mobilizaram e se organizaram em torno do espaço urbano gestado em Volta Redonda para definir seus respectivos interesses. Identificando esses mecanismos poderemos contribuir para o debate sobre a governança urbana nesse contexto e explicar processos mais amplos sobre a especulação do valor da terra por meio de sua acumulação, principalmente por parte da CSN.

No decorrer desta tarefa, identificamos fenômenos muito particulares, principalmente quando pensamos no processo de formação do município. Por exemplo, pensar em um modelo de cidade operária desenvolvida pelos poderes infraestruturais (MANN, 1986) do Estado Novo, por meio da CSN, pode ser um caso de singularidade empírica. Não podemos deixar de pensar nessas particularidades se quisermos avaliar a influência que a CSN e outros atores privados tendem a realizar sobre o espaço urbano, em especial na área do Aero Clube, que trataremos com mais detalhes nessa e na próxima seção.

Considerando essa linha de raciocínio, seguimos as recomendações de Robert K. Yin (2001) e decidimos aplicar o método do estudo de caso para condução de nossa pesquisa. Em uma de suas passagens, o autor explica quando devemos utilizar cada estratégia de pesquisa nas Ciências Sociais, e ao descrever quais tipos de questões o método do estudo de caso é capaz de responder, encontramos similaridades com as questões colocadas por essa pesquisa e também com as estratégias até agora utilizadas:

[...] questões do tipo "como" e "por que" são mais explanatórias, e é provável que levem ao uso de estudos de casos, pesquisas históricas e experimentos como estratégias de pesquisa escolhidas. Isso se deve ao fato de que tais questões lidam com ligações operacionais que necessitam ser traçadas ao longo do tempo, em vez de serem encaradas como meras repetições ou incidências (YIN, 2001, p. 25).

Identificar o porquê de a CSN ter se tornado uma grande proprietária de terras no município e como ela conseguiu mantê-las em seus ativos parece ser um caminho para explicar o processo de especulação imobiliária no município em questão. Além disso, olhar para outros atores que se interessam e disputam o espaço urbano também é uma maneira de explicar o mesmo processo.

É verdade que o método do estudo de caso não é composto por apenas uma técnica. A pesquisa histórica é sim importante para nosso contexto, mas devemos adicionar evidências que não necessariamente entram no repertório de um historiador, caso da observação direta (YIN, 2001) e análise da literatura. O exercício é, na verdade, lidar com a ampla variedade de evidências que podemos encontrar em um estudo de caso e canalizá-las de tal modo que nos ofereça subsídios para responder nossa pergunta de pesquisa.

Esta pesquisa está estruturada em um modelo essencialmente teórico, com revisão de literatura, análise de documentos e instrumentos normativos. Fizemos uma revisão bibliográfica a partir dos trabalhos de Morel (1989), Palmeira (2012) e Lima (2013) para moldar essa conjuntura crítica que delimitamos (1941-1954). Procuramos triangular informações obtidas na revisão de literatura com notícias em revistas e jornais, documentos públicos relacionados ao planejamento urbano, decretos e instrumentos de planejamento 
urbano - em especial o já mencionado PEDI.

Para responder à questão que esse artigo se propõe, não abordaremos as análises marxistas, elitistas e pluralistas. Entendemos que elas não dialogam satisfatoriamente com as perspectivas teóricas da governança e fogem dos padrões estabelecidos para essa seção de revisão bibliográfica. Nosso foco se estabelecerá nas instituições e, portanto, nosso diálogo está firmado nas teorias neoinstitucionalistas com ênfase na vertente histórica (HALL; TAYLOR, 1996).

A ideia para a revisão bibliográfica é discutir e salientar os principais modelos e teorias sobre o processo de decisão, de modo a oferecer uma maior compreensão sobre os limites e possibilidades nesse caso estudado, haja vista que a execução do modelo de company town foi um processo permeado por decisões.

A Ciência Política é notadamente conhecida por ser a "teoria da decisão", uma vez que ela se preocupa com o cálculo dos custos e benefícios e pode atuar pela otimização dos efeitos das decisões. As primeiras teorias decisórias centraram-se na figura de um ator principal, que toma as decisões e tem por objetivo a sistematização de todas as políticas possíveis, para uma análise sistemática similar das consequências de cada alternativa possível e para uma eleição política para servir metas e objetivos separadamente (BRAYBROOKE; LINDBLOM, 1963).

Do ponto de vista dos tomadores de decisão, é válido ressaltar que não existe uma situação de informação plena, o que determina a racionalidade limitada para os processos das políticas públicas. De outro modo, os processos políticos podem ser imprevisíveis em virtude das informações incompletas e falta de claridade de valores (BRAYBROOKE; LINDBLOM, 1963). Portanto, não é um processo pautado pela racionalidade sinóptica. Não seguiremos essa linha de raciocínio, pois o debate sobre o aspecto de racionalidade completa da escolha já foi amplamente criticado e superado pela academia, demonstrando que é impossível ter controle e conhecimento sobre todas as variáveis ao tomar uma decisão. Veremos outras contraposições ao modelo racional ao longo desta seção.

Simon (1965) conclui que o bom conhecimento do processo decisório tem por finalidade antecipar as consequências das estratégias adotadas através da avaliação das consequências da escolha. Podemos dizer que o autor foi inovador ao romper com antigas concepções sobre as teorias comportamentais vigentes no campo das organizações, que tinham como base as decisões sinópticas. O autor, diferentemente, centrou sua interpretação sobre a decisão no conceito de racionalidade limitada. A partir dessa perspectiva, a racionalidade dos indivíduos seria limitada por diversos fatores, como é o exemplo da falta de informações disponíveis, escassez de tempo e de recursos, além das capacidades cognitivas que os decisores dispõem para tomar uma decisão (MARQUES, 2013).

Podemos dizer que a análise dos processos se torna mais interessante e realista da década de 1970 em diante, pois as novas teorias apontavam para as interações estabelecidas entre atores diversos que buscam influenciar o processo político a fim de garantir uma direção favorável aos seus repertórios de ação coletiva (TILLY, 2010).

Conforme complementa David Easton, a vida política é conceituada como um conjunto complexo de processos, dos quais certas espécies de inputs são convertidas em tipos 
de outputs que podemos chamar de políticas autoritárias, decisões e ações (EASTON, 1970). Essa é uma boa contribuição, pois nos permite refletir como certas demandas são convertidas em políticas através do Estado e suas instituições, no caso, como o projeto de modernização das bases industriais do Estado Novo culminou em decisões e implementação de políticas públicas que dariam origem a CSN e permitiriam seu pleno desenvolvimento.

Paralelamente, o artigo A garbage can model of organization choice trouxe uma visão diferente sobre os processos de tomada de decisão. O trabalho foi escrito pelos autores Cohen, March e Olsen (1972) e tornou-se uma referência para a literatura sobre processos de escolha, principalmente pelo fato de ser um dos primeiros métodos emulados computacionalmente e que impulsionou o abandono ao método da escolha racional. Segundo os autores, para entender os processos internos à organização deve-se imaginar uma "lata de lixo" onde vários tipos de problemas e soluções estão despejados através da ação dos participantes na medida em que são gerados. Enquanto modelos tradicionais, como vimos, consideravam que a oportunidade da escolha implicava: primeiro a geração de alternativas de decisão, depois o exame de suas consequências e a avaliação dessas consequências e finalmente uma decisão; o modelo da "lata de lixo", por sua vez, considera que a decisão é um resultado ou interpretação de vários fluxos relativamente independentes dentro de uma organização.

De modo complementar, Eduardo Marques traz outros elementos importantes para o modelo garbage can, indicando que na verdade os gestores escolhem o problema a enfrentar em função das capacidades administrativas existentes:

O processo teria, portanto, um caráter bastante inercial e direcionado pelas capacidades do Estado: a existência de soluções prévias levaria à escolha de certos problemas e não ao contrário, como imaginado até então (MARQUES, 2013, p. 32).

Além da crítica à centralidade da racionalidade, o modelo trouxe para a discussão elementos institucionais relativos ao formato do Estado, antecipando uma crítica que foi realizada também pelos neoinstitucionalistas durante a década de 1980 (MARQUES, 2013). Veremos mais detalhes sobre o neoinstitucionalismo logo adiante.

Nos anos de 1970 novos trabalhos e análises surgiram, como é o exemplo do "enfoque da interação" tecido pelos autores Lindblom e Cohen (1979), e as "teorias de definição de agenda" propostos por Cobb e Elder (1983), além da expressiva contribuição de Kingdon (2003).

Marques (2013) reforça que nos últimos cinquenta anos evidenciou-se grande diminuição na importância da abordagem racional e também da centralidade do processo de decisão para a análise das políticas públicas. O centro da análise estabeleceu-se também nos processos de formação da agenda e de implementação, ampliando a relevância das agências, burocracias e atores na produção de políticas públicas. Na visão do autor, tal centralidade deve-se à crescente politização e do papel das ideias e valores no processo que envolve as políticas públicas, pois estas são:

[...] entendidas cada vez mais como processos complexos, atravessados por diversas dinâmicas de poder, embora em constante interação com os ambientes 
institucionais, relacionais e cognitivos que as cercam, ambiente esses também construídos ativamente pelos atores. (MARQUES, 2013 p. 24).

A década de 1970 marca um deslocamento de grande porte das análises, tendo a implementação ganhado maior notoriedade frente às demais partes do processo. Já apresentamos algumas pistas iniciais sobre o motivo desse destaque, mas agora iremos apresentar a literatura que discute as especificidades da implementação. Dessa literatura devemos reter a ideia da multiplicidade de atores em interação com o Estado e com as políticas.

A primeira a ser abordada é a obra de Pressman e Wildavsky (1973), principalmente por ter sido uma referência durante a primeira geração dos estudos sobre implementação. Os autores tinham como objetivo apresentar um panorama sobre o processo de implementação de políticas públicas no município de Oakland, apontando as tensões, desafios, erros e acertos de um grande projeto que visava criar empregos e gerar renda para população em situação de vulnerabilidade.

Para Pressman e Wildavsky a meta e os atos de implementação são parte do processo de interação, onde cada elemento depende do outro. A implementação jamais pode ser encarada como uma pura relação entre meios e fins.

Devido à limitação cognitiva do ser humano e a qualidade dinâmica do ambiente, é impossível conhecer todas as restrições pertinentes à implementação. Já em relação ao conteúdo das políticas, os autores inferem que elas configuram a implementação, delimitando o campo onde tenha lugar, o processo, a identidade, o papel dos principais participantes e a variedade dos instrumentos.

Para além disso, sabemos que os recursos financeiros e operacionais são finitos, geralmente as informações são incompletas e também que a implementação depende de um arranjo de interação entre inúmeros atores.

Até o momento falamos sobre o processo de decisão e como ele se transformou ao longo dos anos de 1950 e 1970. Tangenciamos as organizações, mas ainda não colocamos a ênfase necessária nas instituições do Estado.

A partir dos anos 1980 ocorre um novo deslocamento do estudo de políticas públicas no âmbito da Ciência Política, desta vez, sobre influência das teorias neoinstitucionalistas. As três principais correntes neoinstitucionalistas são a da escolha racional, a histórica e a sociológica (HALL; TAYLOR, 1996). Embora as três possuam diferenças intrínsecas, o que há de comum entre elas é a centralidade dada às instituições e o que não há é uma teoria unificada, mas sim, um campo de análise amplo e heterogêneo.

Para a construção de pontos de contato entre nosso objeto de pesquisa, e explicá -lo utilizando as teorias sobre governança será especialmente importante focar a abordagem no neoinstitucionalismo histórico.

O neoinstitucionalismo histórico desenvolveu-se como uma reação contra o estruturo-funcionalismo, se empenhando em ultrapassá-lo. O principal ponto para nossa discussão é com relação aos grupos. Devemos reter a ideia de que o conflito entre grupos rivais pela apropriação de recursos escassos é central à vida política, pensando especialmente na distribuição desigual do poder e dos recursos. De acordo com essa literatura, parte das 
explicações são encontradas no modo como a organização institucional da comunidade política e das estruturas econômicas entram em conflito, fazendo com que determinados interesses sejam privilegiados em detrimento de outros (HALL; TAYLOR, 1996).

Essa corrente teórica define as instituições como os procedimentos, protocolos, normas e convenções oficiais e oficiosas inerentes à estrutura organizacional da comunidade política e econômica. Traz ainda elementos de assimetrias de poderes associados ao funcionamento e desenvolvimento dessas instituições. Portanto, concordamos com a ideia de que há uma grande centralidade e influência das instituições na esfera da política (SKOCPOL, 1985). De outro modo, a teoria busca combinar explicações da contribuição das instituições à determinação de situações políticas, mas não se limitando a isso. Há também a associação de outros fatores como é o exemplo das ideias, aplicada a esses mesmos processos.

Essa breve contextualização de elementos associados à teoria do neoinstitucionalismo histórico servirá como um elo de ligação para discutir as teorias de governança que serão apresentadas na sequência. Dessa exposição, devemos guardar um aspecto fundamentalmente importante para realizar essa ponte: o neoinstitucionalismo recuperou uma visão weberiana de Estado e trouxe a dinâmica política para seu interior. Essa afirmação é especialmente importante para tratarmos da governança, pois sabemos que essa análise permite dizer que o processo de produção de políticas públicas dependerá da interação entre o Estado e os agentes presentes na sociedade e em ambientes institucionais específicos (MARQUES, 2013).

Acreditamos no potencial de enquadramento que a teoria da governança nos fornece para entender os processos de mudança de governo, identificação de questões, respostas relevantes e alguns pressupostos que desafiam a administração pública e os processos de decisão.

Conforme apontou Stoker (1998), as raízes teóricas da governança são variadas e, em alguns casos, a literatura acadêmica se apresenta de forma eclética e desconexa. É fato que a diversidade traz grandes contribuições, mas é preciso elaborar uma perspectiva para pensar a governança. De forma sintética, queremos pensar na governança como uma lente analítica que nos permita olhar para a intermediação de diferentes interesses, recursos e visões dos atores políticos e sociais. Essa não é uma tarefa trivial, pois esse termo é polissêmico, disputado e sujeito a uma diversidade de interpretações, tornando impossível qualquer definição apriorística.

Nossa ideia é assumir o significado de governança como uma "nova forma" de governo, por considerar que ela é expressão de um arranjo decisório não hierárquico de produção e implementação de políticas públicas (PETERS; PIERRE, 2010). Isso nos permite dizer que as correntes de governança na organização pública dão a ela um caráter multifuncional (RAINEY, 2014), pois diferentemente das organizações privadas, elas lidam com diversos conflitos de considerações, como a direção política, o controle, a representação e a participação.

No contexto de Volta Redonda há, na verdade, um conjunto de atores que disputam esse espaço urbano em arenas politizadas, conforme verificamos em uma das reuniões de 
criação do Plano Diretor Participativo de Volta Redonda (PDP-VR) aprovado em 2008.

O que desejamos analisar nesse caso específico é como operam os arranjos de governança urbana em Volta Redonda a partir do que foi colocado por Marques (2016), quando destacou a importância dos capitais do urbano para o detalhamento das políticas urbanas locais. Tendo rejeitado a ideia de pura captura do Estado pelos capitais, especialmente daqueles ligados aos processos gerais de acumulação, a ideia do autor foi estabelecer a importância do capital como uma espécie de influência na produção de políticas públicas, através de estratégias políticas em conexão com diversos atores que se envolvem direta ou indiretamente com as instituições que produzem as políticas.

Para tornar mais claro o funcionamento dos arranjos de governança e o processo de especulação de imóveis concordamos com o autor, que parte da premissa que os capitais que mais se interessam por influenciar as políticas urbanas são os capitais que têm seus circuitos de valorização diretamente associados à cidade (MARQUES, 2016). Para esse tipo de capital, as características e as políticas urbanas são fatores relevantes, por isso que pensar o modelo de produção do espaço urbano organizado a partir de uma lógica de company town torna-se fundamental, principalmente quando consideramos tudo o que foi exposto na seção anterior.

Na seção seguinte veremos os resultados da pesquisa. Indicaremos os caminhos que nos levaram a crer que de fato existe um potencial interesse da CSN e de outros atores privados na atividade de especulação dentro do território de Volta Redonda.

\section{COMPANY TOWN E ESPECULAÇÃO IMOBILIÁRIA: LEVANTAMENTOS E ANÁLISE}

Optamos por separar a presente seção em duas subseções, que correspondem as duas dimensões analisadas. A primeira dimensão se ocupa especificamente dos interesses da CSN perante uma área denominada como Aero Clube. Trata-se de uma expressiva porção de terras que encontram-se ociosas até os dias atuais, mas que surgem a partir de um decreto de expropriação chancelado durante o horizonte temporal que propomos nesta análise. A segunda subseção alude aos interesses de um grupo de atores que se aproveitaram do modelo de gestão de cidade empresa e executaram uma série de atividades irregulares e até mesmo ilegais para realizar a promoção da especulação junto à prefeitura logo nos estágios iniciais da emancipação do município. Essas duas diferentes dimensões, quando somadas, nos permitem verificar os meios como se deram as atividades iniciais de especulação imobiliária no contexto de uma company town.

\section{A Companhia Siderúrgica Nacional e as glebas ociosas do Aero Clube}

As terras anteriormente citadas, do Aero Clube, são um grande vazio urbano que pertencem à CSN atualmente. As disputas por elas são percebidas de diferentes formas e permeadas por diferentes atores, dependendo do contexto no qual eles se inserem. Ao adotarmos a área do Aero Clube como nosso objeto de investigação no espaço urbano e 
incluí-la dentro do contexto de nossa conjuntura crítica de análise, torna-se mais clara a tarefa de identificar como a CSN e seus respectivos interesses se relacionam com esse espaço urbano ao longo do período analisado.

O Aero Clube surge por meio do Decreto-Lei n² 237/1941 (MPF-RJ, 2015, fl. 5), que garantia à Companhia a desapropriação de terras no município, promovidas pela União e pelo Estado, e foi baixado pelo então interventor federal do Rio de Janeiro. O nome Aero Clube foi escolhido porque inicialmente essas terras seriam destinadas à construção de um aeroporto, e foram desapropriadas com prerrogativas de utilidade pública antes da privatização da CSN (MPF-RJ, 2015, fl. 5). Aparentemente a CSN, a União e o Estado tinham interesses para essa área na ocasião de sua desapropriação, uma vez que o Decreto $\mathrm{n}^{\circ}$ 2.206, de 10 de abril de 1945 chancela uma decisão:

\begin{abstract}
declara de utilidade pública, para fins de desapropriação, uma área de terras com cerca de um milhão e quinhentos mil metros quadrados, na margem esquerda do rio Paraíba, e que consta pertencer a herdeiros de Aprigio Barreira Cravo. A desapropriação tem por finalidade a construção de um campo de pouso para aeronaves, sendo o imóvel expropriado em favor da Companhia Siderúrgica Nacional (MPF-RJ, 2015, fl. 5).
\end{abstract}

Interessante é notar que essa área desapropriada por utilidade pública passou a ser um lote privado após a privatização da CSN. Há diversos questionamentos sobre os aspectos legais da transferência de terras para a CSN depois de sua privatização e isso é discutido amplamente em um Parecer do Ministério Público Federal do Rio de Janeiro (MPF-RJ). O Parecer é apropriado também para triangular informações e dar base de sustentação para nossos argumentos, considerando que ele discorre, praticamente em sua totalidade, sobre os custos legis e inquéritos civis públicos sobre o patrimônio da empresa, sendo um deles a área do Aero Clube. Por hora, desejamos compreender o possível jogo de interesses que foi se construindo em torno desse espaço urbano.

Se inicialmente essa área do Aero Clube seria destinada à construção de um aeroporto e por isso teria sido desapropriada pela CSN, em 2005 os planos iniciais sofreriam alguma mudança. Doze anos após a privatização, a ideia era destiná-la à fins comerciais:

[...] mesmo após a fundação da empresa, outras áreas foram desapropriadas pelo governo federal, sendo uma delas destinada à construção de um aeroporto (área do Aero Clube), porém este teria sido desativado após a privatização da empresa, a qual, em 2005, passou a pretender a utilização desta área com fim comercial (MPF-RJ, 2015, fl. 3).

Notamos, portanto, que a CSN teve um imóvel expropriado em seu favor, esse foi mantido em seu conjunto de ativos mesmo após a privatização e ainda teve sua finalidade alterada daquela que foi determinada no decreto.

Considerando esse relato inicial sobre as relações do espaço urbano do Aero Clube, podemos notar que a CSN é um ator que tem potencial interesse na área em questão. Acreditamos nessa possibilidade porque ela conquistou e manteve essas terras em seu conjunto de ativos ao longo do tempo, sabendo da valorização crescente que essas terras teriam. 
Com relação a essa área específica e outros ativos da empresa, vale ressaltar que a posição do MPF-RJ é a de reforçar a ilegalidade da transferência de patrimônios imóveis para a CSN no ato da privatização, conforme salientamos brevemente. O argumento central dos autores do Parecer - quando se trata da área do Aero Clube - está relacionado ao desvio de finalidade da desapropriação, pois como vimos, a área seria destinada inicialmente à construção de um aeroporto. Além disso, não foram encontradas citações sobre essas terras no conjunto de ativos à venda da empresa ainda quando era estatal:

Diante disso, na visão dos autores, tais terras já não pertenceriam, quando da privatização da CSN, ao ativo da empresa, pois teriam revertido ao patrimônio do Estado do Rio de Janeiro em razão da chamada tredestinação (desvio na finalidade de desapropriação). Ao analisar o edital de privatização, em especial o seu anexo III, os autores destacam que não são citadas as terras no cálculo de venda da companhia, tendo sido o preço da empresa calculado com base no seu fluxo de caixa, voltado à produção industrial (MPF-RJ, 2015, fl. 03).

A conclusão dos autores do Parecer nos dá indícios sobre os interesses da CSN para o espaço urbano de um modo geral. Além disso requerem a retomada de ativos que ela consolidou desde quando Volta Redonda seguia o modelo de company town:

Concluem os autores que a CSN se aproveita do fato de tais imóveis estarem registrados em seu nome para lucrar indevidamente sobre as terras, administrando-as como se dona fosse. Com base nisso, busca a retomada de terrenos onde estão instalados hospitais, clubes e espaços públicos importantes da cidade (MPF-RJ, 2015, fl. 3).

Evidenciamos na visão dos autores do Parecer que a CSN de fato planejou utilizar a área do Aero Clube para lucrar indevidamente e exercer a atividade de especulação imobiliária.

A fim de garantir bases mais sólidas para responder à questão de pesquisa e dar concretude a nossos argumentos, apresentamos abaixo a última notícia que temos sobre a destinação do Aero Clube, que tem como fonte um jornal de circulação local, chamado Diário do Vale ${ }^{3}$. Na matéria publicada em 29 de julho de 2015, representantes da CSN e do escritório de arquitetura Loeb Capote apresentam um projeto para o secretário de planejamento e o vice-prefeito de Volta Redonda:

Na versão apresentada também para o secretário municipal de Planejamento, Lincoln Botelho, e o vice-prefeito Carlos Roberto Paiva, o arquiteto Roberto Loeb detalhou a ocupação final do terreno - que tem cerca de 675 mil metros quadrados [valor inferior ao da metragem prevista no decreto de desapropriação], no total que prevê a construção de um shopping center, com $200 \mathrm{mil} \mathrm{m}^{2}$ de área, uma torre com 240 metros de altura (equivalente a 80 andares), com restaurante e pontos de observação, uma avenida para pedestres com 450 metros de extensão e 15 metros de largura, um mercado municipal, além de uma grande área verde e prédios mistos, comerciais e residenciais.

\footnotetext{
${ }_{3}^{3}$ Disponível em: http://diariodovale.com.br/economia/csn-apresenta-versao-final-do-projetopara-ocupacao-de-terreno-no-aero/
} Último acesso: 05/04/2018 
Não passa despercebido a maneira como o Aero Clube teve suas destinações alteradas. Tudo isso nos dá indícios sobre como a Companhia se organizou para transformar uma área que outrora seria destinada a implementação de um aeródromo para uma que viabilizasse a exploração comercial com alto viés de rentabilidade financeira ${ }^{4}$. Certamente há irregularidades na transferência de terras públicas para a empresa privatizada. Embora essas irregularidades não sejam o cerne de nossa questão, verificamos que de fato há atividades lucrativas em relação a este espaço urbano.

Na próxima subseção abarcaremos outros atores privados relevantes, na tentativa de demonstrar, mais uma vez, como se iniciou o processo de especulação imobiliária em Volta Redonda.

\title{
O aparente fim do modelo de company town e a aprovação em massa de lotes clandestinos
}

Um ponto importante com relação ao desenvolvimento do município é o "processo de segregação planejada", expressão frequentemente utilizada por autores que discutem o contexto de formação de Volta Redonda e que se traduz em elementos importantes para essa pesquisa em andamento. Regina Morel elucida de maneira muito clara os traços desse processo:

\begin{abstract}
Santo Antônio de Volta Redonda [nome conferido ao distrito] ficaria dividida em duas: à margem direita do rio, desenvolvia-se o núcleo urbano a partir da conjugação do Plano de Implantação da Usina - seria a "cidade nova"; à margem esquerda, a "cidade velha", separada da CSN e que não dispunha dos serviços da parte planejada. Os antigos habitantes não aproveitados pela CSN foram deslocadas para a parte "velha" ou para a periferia da cidade e os grandes proprietários da região ali se converteram em loteadores e especuladores de terrenos (MOREL, 1989, p. 65).
\end{abstract}

Nas palavras de Morel, a cidade vai se desenvolvendo sob uma dupla configuração: a Cidade Nova e a Cidade Velha. Esse tipo de formação nos permite inferir que as áreas de expansão desordenada obtiveram um maior potencial de êxito para ações de atores envolvidos com a especulação e com o loteamento clandestino. Em outras palavras, o modelo de cidade industrial planejada de fato favoreceu ações irregulares que no contexto de outras cidades talvez não tivessem ocorrido. Essa passagem deixa claro que o processo de formação de Volta Redonda é caracterizado por algumas particularidades. Vale ainda ressaltar que estamos relatando uma época que ainda inexistia o poder público municipal, ficando a CSN encarregada de executar o modelo de company town.

Morel traz em sua obra um relato interessante sobre um ex-empregado da CSN que se converteu num poderoso agente imobiliário. Ele dizia ter encontrado nos serviços de topografia e de loteamento uma ocupação muito mais rentável. Em uma entrevista concedida à autora, ele relata os caminhos para conquistar tal feito, após deixar a CSN em 1949:

${ }^{4}$ Devemos salientar que não foi identificado interesse em especulação imobiliária por parte da Companhia Siderúrgica Nacional (CSN) no período de desapropriação do Aero Clube. Tal fato parece ter se consumado a partir do processo de privatização da CSN ocorrido em 1993. 
Mas eu, a essas alturas dos acontecimentos [realizando trabalho braçal na usina], estava fazendo meu serviço de topografia aqui fora [da cidade planejada], pegando serviço de topografia. E com meus biscates de topografia eu ganhava muito mais do que o salário da CSN. Mas eu verifiquei que fazer o serviço de topografia e a planta não era o grande negócio. O grande negócio era fazer o loteamento próprio. Mas eu não tinha dinheiro para comprar a terra. Então, a partir de um certo período eu modifiquei o meu sistema. O proprietário de terra me procurava para fazer o serviço. Me perguntava: “qual é o seu preço?” Eu dizia: “Não é nada; é de graça. A planta não custa nada. Agora, o senhor me dá exclusividade na venda. Eu quero exclusividade na venda. A minha comissão é de dez por cento. Eu vendo, eu cobro, eu faço tudo'. Passei a ser corretor. Então eu fazia a planta e recebia a corretagem. $E$, depois, verifiquei que o melhor era vender lotes e não era ser corretor, não (MOREL, 1989, p. 251). .

Segundo essa mesma fonte entrevistada, em 1954 já haviam 59 loteamentos em Volta Redonda na área não administrada pela CSN. Esses loteamentos se expandiam beneficiando-se da ausência de controle municipal, gerando um poderoso e influente grupo de atores com interesses próprios na ocupação e no processo de valorização do solo, grupo este que em 1954 iniciou o movimento pela emancipação do município.

Conforme apontamos na subseção anterior, a partir dos dados do relatório do MPF-RJ, nessa mesma época a CSN começava a desapropriar terras para a expansão de suas atividades e, em especial, a do Aero Clube por meio do Decreto $\mathrm{n}^{\circ} 2.206$, de 10 de abril de 1945.

É possível notar que no horizonte temporal estabelecido para a análise há uma miríade de atores explorando o território de Volta Redonda de diferentes maneiras e com diversas finalidades, cada um se aproveitando da condição que lhe foi dada. Caberá agora identificar como ficou essa situação no período em que Volta Redonda de fato inicia seu movimento pela emancipação.

Volta Redonda seria criada por meio da Lei $n^{\circ} 2.185$ de 17 de Julho de 1954, convocando as eleições para o dia 3 de outubro do mesmo ano (MOREL, 1989). Relatos indicam a profunda escassez de documentos disponíveis na administração municipal, em especial das plantas dos terrenos na ocasião de sua emancipação. Então, "criou-se a Associação dos Proprietários de Imóveis, cuja primeira atividade foi auxiliar a prefeitura a realizar o levantamento cadastral dos terrenos e seus proprietários" (idem, p. 265). É um tanto contraditório que uma associação de proprietários de imóveis tenha adentrado à prefeitura para a realização dos levantamentos cadastrais e das plantas. Estes são alguns dos instrumentos que dão legibilidade ao Estado (SCOTT, 1999) e sua manipulação poderia garantir certos benefícios a atores que se encontravam em relação direta com a prefeitura. Em uma passagem bastante representativa, a autora Regina Morel traz à tona o processo de aprovação em massa de loteamentos clandestinos destinados a valorização, logo no ano de emancipação do município:

Coincidindo com um momento de forte fluxo migratório para Volta Redonda, devido à atração exercida pela Usina que necessitava de braços para a execução de seus Planos de Expansão, bem como pela expansão de seu parque industrial local e do setor de serviços, o período pós-emancipação se caracterizou por aprovação em 
massa de loteamentos e também pela expansão de loteamentos clandestinos, em áreas de propriedade da Prefeitura ou em terrenos particulares. Aliás, a infra-estrutura criada pela Prefeitura era um elemento determinante na valorização de terrenos, contribuindo para forjar alianças de interesses da Administração Municipal com os proprietários de terras (MOREL, 1989, p. 267).

O levantamento inicial da conjuntura que propomos indica como se deram as primeiras disputas em torno do território de Volta Redonda. Sabemos que o território dispunha de uma dupla configuração, que permitiu, dentre outras coisas, a ação de loteadores clandestinos que, anos mais tarde, estariam auxiliando a prefeitura recém emancipada na elaboração das plantas dos terrenos para o município. Para além disso, temos também a questão do desenvolvimento da própria CSN, que como vimos na subseção anterior, beneficiou-se de um série de decisões baseadas em decretos, que deram a esse ator um enorme poder perante o espaço urbano de Volta Redonda. Poder este que ela manipulou para conseguir executar a especulação imobiliária através de terras que inicialmente eram públicas.

\section{CONCLUSÃO}

Por meio dessa pesquisa podemos concluir que o modelo de company town gestado em Volta Redonda foi capaz de: (i) garantir uma série de vantagens para a CSN através do poder que a ela foi concedido, principalmente no que tange à acumulação de ativos imóveis; e (ii) segregar o espaço urbano em duas dimensões: uma regulada pela CSN e outra não regulada, deixada a mercê de loteadores clandestinos. Ambos os processos nos ajudam a entender como ocorre a especulação imobiliária no âmbito de Volta Redonda.

No primeiro caso a CSN desfrutou da possibilidade de expropriar terras no município para a expansão de suas atividades produtivas, as quais foram qualificadas como utilidade pública, amparando-a assim, em diversas das expropriações realizadas. Após sua privatização notamos algumas reviravoltas em relação ao uso de pelo menos um desses espaços expropriados, que é o caso de Aero Clube. O uso dessa área sofreu um processo de tredestinação e a Companhia passou a pretender o uso dessa localidade para fins comerciais e para a especulação.

No segundo caso vimos que a "segregação planejada" concebida por meio do modelo de company town, permitiu a ação de um grupo de atores interessados no processo de aprovação de loteamentos clandestinos para a posterior realização da atividade de especulação. É importante salientar também que a Associação de Proprietário de Imóveis se tornou um grupo com governança capaz de incentivar o processo de emancipação do município e ainda adentrar à prefeitura, forjando uma poderosa aliança de interesses entre o incipiente poder público municipal e os proprietários de terras, fator último altamente determinante para a valorização das terras. 


\section{REFERÊNCIAS}

BRAYBROOKE, D.; LINDBLOM, C. E. A Strategy of Decision: Policy Evaluation as a Social Process. New York: Free Press, 1963.

COBB, R. W.; ELDER, C. D. Participation in American politics: The dynamics of agenda-building. Baltimore, MD: Johns Hopkins University Press, 1983.

COHEN, Michael D.; MARCH, James G.; OLSEN, Johan P. A garbage can model of organizational choice. Administrative Science Quaterly. Vol 17, n 1, março 1972.

COLLIER, David, SEAWRIGHT, Jason e MUNCK, Gerardo. "The Quest for Standards: King, Keohane and Verba's Designing Social Inquiry". In: BRADY and COLLIER. Rethinking Social Inquiry: Diverse Tools, Shared Standards. Rowman \& Littlefield Publishers: Oxford, pp. 21-51, 2004.

EASTON, D. "Categorias para a análise de sistemas em política". In: Modalidades de análise política. Rio de Janeiro: Zahar Ed, 1970.

HALL, P. e TAYLOR, R. As três versões do neo-institucionalismo. In: Lua Nova, Nº 58, 2003.

HOCHMAN, G. "História e Políticas Públicas". In: MARQUES e FARIA (org.) A política pública como campo multidisciplinar. São Paulo: Editora Unesp, 2013. 282 p.

KINGDON, John W. Agendas; Alternatives and public policies. Longman: Second edition, 2003.

LIMA, R. CSN e Volta Redonda: uma relação histórica de dependência e controle. Política \& Sociedade, v. 12, n. 25, set/dez 2013.

LIMA, Soeli Regina. Capital transnacional, company town e a produção do espaço urbano. Caminhos de Geografia, Uberlândia, v. 9, n. 25, p.158-164, março 2008.

LINDBLOM, C. E.; COHEN, D. K. Usable knowledge: Social Science and social problem solving. New Haven, CT: Yale University Press, 1979.

MANN, Michael. The Autonomous Power of the State: Its Origins, Mechanisms and Results. In: J. A. Hall (ed.) States in History, p.109-136, 1986.

MARQUES, E. "As políticas públicas na Ciência Política". In: MARQUES e FARIA (org.) A política pública como campo multidisciplinar. São Paulo: Editora Unesp, 2013. 282 p.

. De volta aos capitais para melhor entender as políticas urbanas. Novos Estudos CEBRAP, v. 35, n. 2, p. 15-33, jul 2016.

MOREL, Regina Lúcia de Moraes. A ferro e fogo. Construção e crise da "família siderúrgica": o caso de Volta Redonda (1941-1968). São Paulo: Tese de Doutoramento apresentada junto ao programa de Pós-Graduação em Sociologia da Universidade de São Paulo, 1989.

MPF-RJ. Parecer - CSN bens não-operacionais pertencem à União. Novembro, 2015. Disponível em: http://www.prrj.mpf.mp.br/institucional/atuacao/atuacao-do-mpf-na-capital-enos-mu- 
nicipios/atuacao-vredonda/acoes-civis-publicas/parecer-csn-bens-nao-operacionaispertencem-a-uniao/at_download/documento. Último acesso: 12/05/2018.

NORTH, D. Institutions, Institutional Change and Economic Performance, Cambridge: Cambridge University Press, 1990.

PALMEIRA, Andre Franklin. A Nova Face da "Cidade do Aço": Crise do Capital, Trabalho e Hegemonia em Volta Redonda. Niterói: Dissertação de Mestrado apresentada junto ao programa de Pós-Graduação em História da Universidade Federal Fluminense, 2012.

PETERS, G.; PIERRE, J. Introdução. In Peters, G.; Pierre, J. (Org) Administração Pública: coletânea. Brasília: ENAP/UNESP, 2010.

PRESSMAN, J. L. \& WILDAVSKY, A. Implementation: how great expectations in Washington are dashed in Oakland. $3^{a}$ ed. Berkeley: University of California Press, 1973.

SANTOS, W. G. dos. Cidadania e Justiça: a política social na ordem brasileira. Rio de Janeiro, Ed. Campus, 1979. 138 p.

SCOTT, J. Seeing like a State: How Certain Schemes to Improve the Human Condition Have Failed. Yale University Press, 1999.

SIMON, H. Comportamento administrativo - estudo dos processos decisórios nas organizações administrativas. Rio de janeiro, Usaid/FGV, 1965.

SKOCPOL, T. "Bringing the state back in: strategies of analysis in current research". In: EVANS, P.; RUESSCHMEYER, D. e SKOCPOL, T. (org.). Bringing the state back in. Cambridge: Cambridge University Press, 1985.

STOKER, G. Governance as theory: five propositions. International Social Science Journal, 50, (155), 1998.

TILLY, C. Movimentos sociais como política. Revista Brasileira de Ciência Política, n. 3, p. 133160, jan/jul 2010.

YIN, R. K. Estudo de caso: planejamento e métodos. Porto Alegre. Bookman, 2001. Segunda Edição. 200 p.

Aceito em 31/08/2018

\section{SOBRE O AUTOR}

Douglas Vinicius Franco é Graduado em Administração Pública pela Universidade Federal Fluminense (UFF) e mestrando em Gestão de Políticas Públicas pela Universidade de São Paulo (USP). Atualmente é pesquisador júnior no Centro de Estudos da Metrópole (CEM), sediado na USP e no Centro Brasileiro de Análise e 


\author{
Planejamento (CEBRAP). \\ E-mail: douglasvfranco91@gmail.com.
}

\title{
COMPANY TOWN AND REAL ESTATE SPECULATION: A CASE STUDY IN THE CITY OF VOLTA REDONDA-RJ
}

\begin{abstract}
The work in question mobilized the theoretical and analytical framework provided by the theories of governance to explain how the process of real estate speculation occurs in the context of a company town. We will see by means of a case study carried out in the city of Volta Redonda that we can explain such process of valorization of the earth by two different dimensions. The first considers the Companhia Siderúrgica Nacional as a relevant actor to take into account its possessions, part of which was acquired through its power resources when it was still a state industry. The second dimension considers the aspects that relate to the type of regulation of the territory created in the model of a "company city" and the mobilization of private actors in connection with the newly created city hall. We will see at the end that, even taking into account these two dimensions that shed light on different actors and institutions, it is still possible to verify mechanisms for real estate speculation in both. These different looks will give us the first clues to investigate how the most current land valuation processes occur in a municipality with so many peculiarities.
\end{abstract}

Keywords: company town; real estate speculation; Volta Redonda; CSN.

\section{COMPANY TOWN Y ESPECULACIÓN INMOBILIARIA: UN ESTUDIO DE CASO EN EL MUNICIPIO DE VOLTA REDONDA-RJ}

Resumen: El actual trabajo movilizó el marco teórico y analítico proporcionado por las teorías sobre gobernanza para explicar cómo ocurre el proceso de especulación inmobiliaria en el contexto de uma company town. Veremos por medio de un estudio de caso realizado en el municipio de Volta Redonda que podemos explicar tal proceso de valorización de la tierra por dos dimensiones diferentes. La primera considera a la Compañía Siderúrgica Nacional como actor relevante por tener en cuenta sus posesiones, parte de ellas adquiridas por medio de sus recursos de poder cuando aún era una industria estatal. La segunda dimensión considera los aspectos que se relacionan con el tipo de regulación del territorio gestado en el modelo de una "ciudad empresa" y la movilización de actores privados en conexión con la recién creada prefectura. Veremos al final, que incluso teniendo en cuenta esas dos dimensiones que arrojan luz a diferentes actores e instituciones, aún así, es posible verificar mecanismos para la especulación inmobiliaria en ambas. Estas diferentes miradas nos darán las primeras pistas para investigar cómo ocurren los procesos más actuales de valorización de la tierra en un municipio dotado de tantas particularidades.

Palabras clave: company town; especulación inmobiliaria; Volta Redonda; CSN. 